\title{
ANALISIS PENGGUNAAN FRAMEWORK WEBSITE JDIH KHUSUS PERATURAN KEMENTERIAN REPUBLIK INDONESIA
}

\author{
Yahya Noviko Rahman'), Rizal Maulana Hadi²), Mursyidatun Nabilah ${ }^{3)}$, Muhammad Hanif \\ Waskito ${ }^{4)}$, Nur Aini Rakhmawati ${ }^{5}$ \\ 1,2,3,4,5Fakultas Teknologi Elektro dan Informatika Cerdas, Institut Teknologi Sepuluh Nopember, Jl. \\ ITS Raya, Sukolilo, Surabaya \\ email: ${ }^{1}$ rviko51@gmail.com, ${ }^{2}$ rizalmaulana6@gmail.com, ${ }^{3}$ yusi.nabilah@gmail.com, \\ hanifwaskito012@gmail.com, ${ }^{5}$ nur.aini@is.its.ac.id
}

\begin{abstract}
Jaringan Dokumentasi dan Informasi Hukum (JDIH) of Ministry's website is a form of implementation of regulations that state that all things about law are public information, so the public must be able to access information related to legal products from the ministry. For that reason, we try to analyze the framework of each Ministry JDIH website using Wappalyzer by identifying three types of existing frameworks, knowing how the website distributes legal products in terms of appearance and features. And the results of the analysis, there are already several websites that implement a framework to develop it, even though the implementation of the web framework needs to be further improved on the web of the Ministry
\end{abstract}

Keywords : web, framework, jdih, kementerian, Wappalyzer

\begin{abstract}
Abstrak
Website Jaringan Dokumentasi dan Informasi Hukum (JDIH) Kementerian merupakan bentuk implementasi dari adanya peraturan yang menyebutkan segala hal tentang hukum adalah informasi publik, sehingga masyarakat harus dapat mengakses informasi terkait produk hukum dari kementerian. Untuk itu, kami mencoba menganalisis dari framework setiap website JDIH Kementerian menggunakan Wappalyzer dengan mengindentifikasi tiga jenis framework yang ada mengetahui bagaimana website tersebut menyalurkan produk hukumnya dari segi tampilan maupun fitur-fitur yang ada. Dan hasil dari analisis tersebut, sudah terdapat beberapa website yang menerapkan framework untuk mengembangkannya, meski begitu implementasi pada web framework perlu lebih ditingkatkan lagi pada web Kementerian
\end{abstract}

Kata Kunci : web, framework, jdih, kementerian, Wappalyzer

\section{PENDAHULUAN}

Berdasarkan Peraturan Presiden 68 tahun 2019 tentang Organisasi Kementerian Negara, Kementerian golongan I , III , dan III dapat merumuskan dan menetapkan kebijakan di bidangnya[1]. Oleh karena itu 34 Kementerian yang ada di Indonesia mengeluarkan Peraturan Kementerian pada tiap bidang kementerian-nya masing-masing.

Menurut Undang-Undang Nomor 14 Tahun 2008 tentang Keterbukaan Informasi Publik, setiap informasi hukum merupakan kategori Informasi Publik yang wajib disediakan kepada publik[2]. Semua bentuk peraturan dan salah satunya adalah Peraturan Kementerian ini dibentuk dan didokumentasikan dalam Jaringan Dokumentasi dan Informasi Hukum 
Nasional (JDIHN), serta website JDIH khusus kementerian. JDIH merupakan wadah pendayagunaan dokumentasi hukum dan informasi hukum sebagai suatu sarana masyarakat dapat mengetahui tentang hukum dalam menciptakan ekosistem masyarakat yang cerdas hukum[2]. Informasi mengenai hukum tersebut merupakan bagian tugas dari biro JDIH di setiap kementerian, yang termasuk kedalam anggota JDIHN, dimana berlandaskan pada Peraturan Presiden No 33 Tahun 2012 [3].

Penggunaan website digunakan untuk memudahkan akses bagi siapa saja yang ingin mendapatkan informasi hukum di Kementerian. Pada umumnya penggunaan website di badan pemerintahan bukanlah hal baru. Sudah menjadi hal umum untuk badan pemerintah, khususnya Kementerian memiliki website,

Berdasarkan penelitian dari kecepatan yang dimiliki website pemerintah Provinsi sangatlah rendah. Dalam hal konten situs web, penelitian sebelumnya mengungkapkan bahwa kurang dari $60 \%$ situs web resmi pemerintah daerah yang dapat memberikan informasi sebagaimana dinyatakan dalam peraturan Pemerintah Indonesia [4]. Berdasarkan penelitian ini, kami ingin mencoba mengkaji lebih dalam website mengenai peraturan pemerintah di ranah yaitu kementerian, karena website dari kementerian belum banyak diteliti lebih lanjut.

Maka itu, penelitian ini berlandaskan pada Instruksi Presiden Nomor 3 Tahun 2003 tentang kebijakan dan strategi nasional pengembangan E-Government yang menyatakan bahwa untuk mencapai pengembangan dan pengimplementasian E-Government yang sempurna harus dilakukan evaluasi yang menyeluruh dan secara terus menerus[5]. Penelitian ini berfokus pada evaluasi tentang bagaimana, Website JDIH Kementerian tersebut dapat dengan mudah menampilkan produk-produk hukum yang ingin dicari masyarakat, dan analisis penggunaan framework dalam pembuatan Web JDIH tersebut.

Dari latar belakang tersebut, maka penelitian ini bertujuan untuk :

1. Evaluasi penggunaan Website JDIH Kementerian, dalam hal pencarian produkproduk hukum yang ada di kementerian terkait dalam memudahkan masyarakat mendapatkan informasi hukum

2. Analisis penggunaan framework dalam pembuatan Web JDIH Kementerian.

\section{TINJAUAN PUSTAKA}

\subsection{Jaringan Dokumentasi dan Informasi Hukum Nasional (JDIHN)}

Jaringan Dokumentasi dan Informasi Hukum Nasional yang selanjutnya disingkat JDIHN adalah wadah pendayagunaan bersama atas dokumen hukum secara tertib, terpadu, dan berkesinambungan, serta merupakan sarana pemberian pelayanan informasi hukum secara lengkap, akurat, mudah, dan cepat[3]. JDIHN merupakan sebuah organisasi yang dibentuk dengan tujuan untuk mengelola dokumentasi informasi hukum dari berbagai instansi pemerintah agar ketersediaan dokumen hukum dapat ter-dokumentasi dengan jelas, lengkap untuk mendukung reformarsi hukum.Organisasi JDIHN terdiri atas Pusat JDIHN dan Anggota JDIHN[3]. Bahan dokumen hukum tersebut dianggap penting karena dokumen hukum adalah produk hukum berupa peraturan perundang-undangan dan instrumen hukum lainnya yang meliputi namun tidak terbatas pada putusan pengadilan, yurisprudensi, monografi hukum, artikel majalah hukum, penelitian hukum, pengkajian hukum, naskah akademis, dan rancangan peraturan perundang-undangan dan instrumen hukum lainnya[3]. 


\subsection{Web JDIH Kementerian}

Website Jaringan Dokumentasi dan Informasi Hukum Kementerian adalah tindak lanjut dari adanya Jaringan Dokumentasi dan Informasi Hukum Nasional (JDIHN) yang dibentuk dengan tujuan untuk mengelola dokumentasi informasi hukum dari Kementerian agar ketersediaan dokumen hukum dapat ter-dokumentasi dengan jelas, lengkap untuk mendukung reformarsi hukum[3]. Kementerian Negara sebagai badan publik yang fungsi dan tugas pokoknya berkaitan dengan penyelenggaraan negara, maka wajib memberikan informasi publik, dengan menimbang bahwa keterbukaan informasi publik merupakan sarana dalam mengoptimalkan pengawasan publik terhadap penyelenggaraan negara dan Badan Publik lainnya dan segala sesuatu yang berakibat pada kepentingan publik[1]. Maka dari hal tersebut adanya website JDIH Kementerian berfungsi untuk memenuhi kebijakan-kebijakan tersebut. Bentuk website dipilih untuk memudahkan integrasi antara JDIH Kementerian dengan JDIHN Pusat.

\subsection{Web Frameworks}

Web frameworks merupakan sebuah alat yang membantu untuk membangun sebuah website untuk menghindari bug dan menghemat waktu. Web framework dapat digunakan baik untuk halaman web statis maupun dinamis. Kita dapat memilih framework tergantung pada kebutuhan yang ada[6]. Laravel, Meteor, Microsoft ASP.NET, CodeIgniter, dan Koala Framework merupakan contoh dari web framework.

\subsection{Javascript Frameworks}

Javascript framework merupakan kerangka kerja aplikasi web yang dituliskan dalam bahasa pemrograman Javascript, framework ini menjelaskan bagaimana aplikasi perlu dibangun dan memungkinkan kode untuk dapat digunakan kembali dan lebih terorganisir serta memperkuat skalabilitas dan fleksibilitas aplikasi[7]. Sejak awal munculnya internet, situs web dibagi menjadi dua komponen, yaitu server-side dan client-side. Ketika serverside dikelola oleh berbagai macam framework dan bahasa pemrograman, client-side didominasi oleh penggunaan JavaScript[8]. AlloyUI, AMP, Angular merupakan contoh dari Javascript Frameworks

\subsection{UI Frameworks}

User interface atau antarmuka pengguna adalah suatu istilah untuk tampilan komputer, dalam hal ini website yang berinterakasi langsung dengan pengguna. Tampilan UI ini sangat dan perlu diperhatikan untuk membuat tampilan yang bagus[9]. Sedangkan menurut Betha Sidik (2012) Framework adalah " kumpulan intruksi-intruksi yang dikumpulkan dalam class dan function-function dengan fungsi masing-masing untuk memudahkan developer dalam memanggilnya tanpa harus menuliskan syntax program yang sama berulang-ulang serta dapat menghemat waktu'[10]. Sehingga dapat ditarik kesimpulan bahwa UI Framework adalah kumpulan fungsi atau libraries yang bertujuan agar developer suatu web menghemat waktu untuk menggunakan suatu fungsi tertentu. UI Frameworks berfungsi untuk mengatur tata letak maupun animasi, yang akan ditampilkan dalam web tersebut. Angular Material, animate.css, bootstrap, dan lainnya merupakan contoh dari UI Frameworks. 


\section{METODE PENELITIAN}

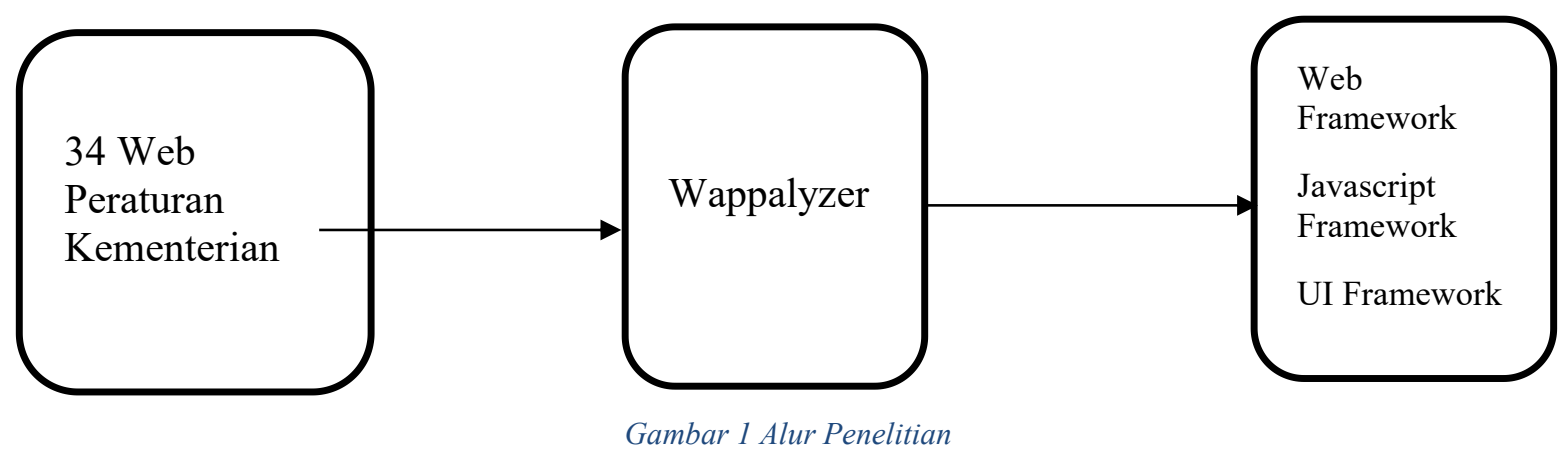

Metode pengumpulan data yang kami gunakan adalah dengan menggunakan aplikasi Wappalyzer (https://wappalyzer.com). Wappalyzer merupakan software multi-platform berupa ekstensi web browser yang dapat mengidentifikasi teknologi yang digunakan dalam suatu website. Wappalyzer dapat mengidentifikasi content management systems, ecommerce platforms, web frameworks, server software, dan analytics tools. Wappalyzer adalah aplikasi yang dapat digunakan untuk melakukan sebuah pengambilan informasi dari sebuah aplikasi yang digunakan pada suatu website yang disebut sebagai fingerprint information yang mana informasi ini dicocokkan dengan fingerprint information yang terdapat pada database wappalyzer sehinga dapat menampilkan secara jelas teknologi apa yang digunakan pada pembuatan sebuah website [11] . Data yang telah terkumpul kami bentuk dalam sebuah format excel agar dapat memudahkan analisa penggunaan teknologi yang ada pada website JDIH dan kami publikasikan dataset di Zenodo [12],

Pertama kami mencari alamat web JDIH setiap kementerian dengan bersumber pada website JDIHN (http://jdihn.go.id/). Terdapat 34 Kementerian periode 2019-2024 yang akan dianalisis beserta jumlah peraturan yang disertakan di halaman websitenya.

Tabel 1 Nama Kementerian dan Jumlah Peraturan

\begin{tabular}{|c|c|c|c|}
\hline No & $\begin{array}{c}\text { Nama Kementerian (Jumlah } \\
\text { Peraturan) }\end{array}$ & No & Nama Kementerian \\
\hline 1 & $\begin{array}{l}\text { Kementerian Dalam Negeri (1322 } \\
\text { peraturan) }\end{array}$ & 18 & $\begin{array}{l}\text { Kementerian } \\
\text { peraturan) }\end{array}$ \\
\hline 2 & $\begin{array}{llll}\begin{array}{l}\text { Kementerian } \\
\text { peraturan })\end{array} & \text { Luar } & \text { Negeri } & (87 \\
\end{array}$ & 19 & $\begin{array}{l}\text { Kementerian } \\
\text { peraturan) }\end{array}$ \\
\hline 3 & $\begin{array}{l}\text { Kementerian } \\
\text { peraturan) }\end{array}$ & 20 & $\begin{array}{l}\text { Kementerian } \\
\text { peraturan) }\end{array}$ \\
\hline 4 & Kementerian Agama (863 peraturan) & 21 & $\begin{array}{l}\text { Kementerian Riset dan Teknologi (286 } \\
\text { peraturan) }\end{array}$ \\
\hline
\end{tabular}




\begin{tabular}{|c|c|c|c|}
\hline 5 & $\begin{array}{l}\text { Kementerian Agraria dan } \\
\text { Ruang (354 peraturan) }\end{array}$ & 22 & Kementerian Sosial (273 peraturan) \\
\hline 6 & $\begin{array}{l}\text { Kementerian Desa, Pembangunan } \\
\text { Daerah tertinggal, dan Transmigrasi } \\
\text { (141 peraturan) }\end{array}$ & 23 & $\begin{array}{l}\text { Kementerian Sekretariat Negara }(94 \\
\text { peraturan) }\end{array}$ \\
\hline 7 & $\begin{array}{l}\text { Kementerian Energi dan Sumber } \\
\text { Daya Mineral (523 peraturan) }\end{array}$ & 24 & $\begin{array}{l}\text { Kementerian Koperasi dan Usaha Kecil } \\
\text { (116 peraturan) }\end{array}$ \\
\hline 8 & $\begin{array}{l}\text { Kementerian Hukum dan HAM (408 } \\
\text { peraturan) }\end{array}$ & 25 & $\begin{array}{l}\text { Kementerian } \\
\text { Perempuan dan Perlindungan Anak } \\
\text { (137 peraturan) }\end{array}$ \\
\hline 9 & $\begin{array}{l}\text { Kelautan dan Perikanan } \\
\text { an) }\end{array}$ & 26 & $\begin{array}{l}\text { Kementerian Pendayagunaan Aparatur } \\
\text { Negara dan Reformasi Birokrasi } \\
\text { Indonesia ( } 721 \text { peraturan) }\end{array}$ \\
\hline 10 & $\begin{array}{l}\text { Kementerian } \quad \text { Kesehatan } \quad(530 \\
\text { peraturan })\end{array}$ & 27 & \begin{tabular}{rr}
\multicolumn{2}{r}{ Perencanaan } \\
Nasional $\quad(1329$
\end{tabular} \\
\hline 11 & $\begin{array}{l}\text { Kementerian } \text { Ketenagakerjaan }(897 \\
\text { peraturan) }\end{array}$ & 28 & $\begin{array}{l}\text { Kementerian Badan } \\
\text { Negara (386 peraturan) }\end{array}$ \\
\hline 12 & $\begin{array}{l}\text { Kementerian } \quad \text { Keuangan } \quad(3358 \\
\text { peraturan })\end{array}$ & 29 & $\begin{array}{l}\text { Kementerian Pemuda dan Olahraga } \\
\text { (160 peraturan) }\end{array}$ \\
\hline 13 & $\begin{array}{l}\text { Kementerian Komunikasi dan } \\
\text { Informatika (440 peraturan) }\end{array}$ & 30 & $\begin{array}{l}\text { Kementerian Pariwisata dan Ekonomi } \\
\text { Kreatif ( } 609 \text { peraturan) }\end{array}$ \\
\hline 14 & $\begin{array}{l}\text { Kementerian Lingkungan Hidup dan } \\
\text { Kehutanan ( } 947 \text { peraturan) }\end{array}$ & 31 & $\begin{array}{l}\text { Kementerian Koordinasi Bidang } \\
\text { Politik, Hukum, dan Keamanan }(8 \\
\text { peraturan })\end{array}$ \\
\hline 15 & $\begin{array}{l}\text { Kementerian Pekerjaan Umum dan } \\
\text { Perumahan Rakyat (678 peraturan) }\end{array}$ & 32 & $\begin{array}{lcc}\text { Kementerian } & \text { Koordinator } & \text { Bidang } \\
\text { Perekonomian }(101 \text { peraturan }) & \end{array}$ \\
\hline 16 & $\begin{array}{l}\text { Kementerian } \quad \text { Pendidikan } \\
\text { Kebudayaan (1707 peraturan) }\end{array}$ & 33 & $\begin{array}{lrr}\text { Kementerian } & \text { Koordinator } & \text { Bidang } \\
\text { Pembangunan } & \text { Manusia } & \text { dan } \\
\text { Kebudayaan (115 peraturan) } & \end{array}$ \\
\hline 17 & $\begin{array}{lll}\begin{array}{l}\text { Kementerian } \\
\text { peraturan })\end{array} & \text { Perdagangan } & (466 \\
\end{array}$ & 34 & $\begin{array}{l}\text { Kementerian Koordinasi } \quad \text { Bidang } \\
\text { Kemaritiman dan Investasi Indonesia } \\
(350 \text { peraturan) }\end{array}$ \\
\hline
\end{tabular}

Setelah ditemukan seluruh alamat web produk hukum kementerian, kami melakukan analisis dengan Wappalyzer. Terdapat batasan data yang dapat dikumpulkan karena keterbatasan kemampuan dari Wappalyzer itu sendiri. Setelah menganalisis web 
Kementerian menggunakan aplikasi Wappalyzer, data diolah menggunakan excel. Dimana penyajian data ditampilkan menggunakan chart untuk memudahkan dalam mengambil informasi yang ada dari data tersebut.

\section{HASIL DAN PEMBAHASAN}

Hasil dari identifikasi terkait keberadaan Web JDIH Kementerian, menghasilkan diagram pie seperti gambar dibawah ini. Dimana didapatkan hasil bahwa masih ada kementerian yang belum memiliki web khusus untuk mendokumentasi hukum kementerian terkait (JDIH). Dari 34 kementerian, 12\% atau 4 Kementerian masih belum memiliki web khusus JDIH. Kementerian tersebut antara lain adalah Kementerian Hukum dan HAM, Kementerian Kesehatan, Kementerian Koperasi dan Usaha Kecil, dan Kementerian

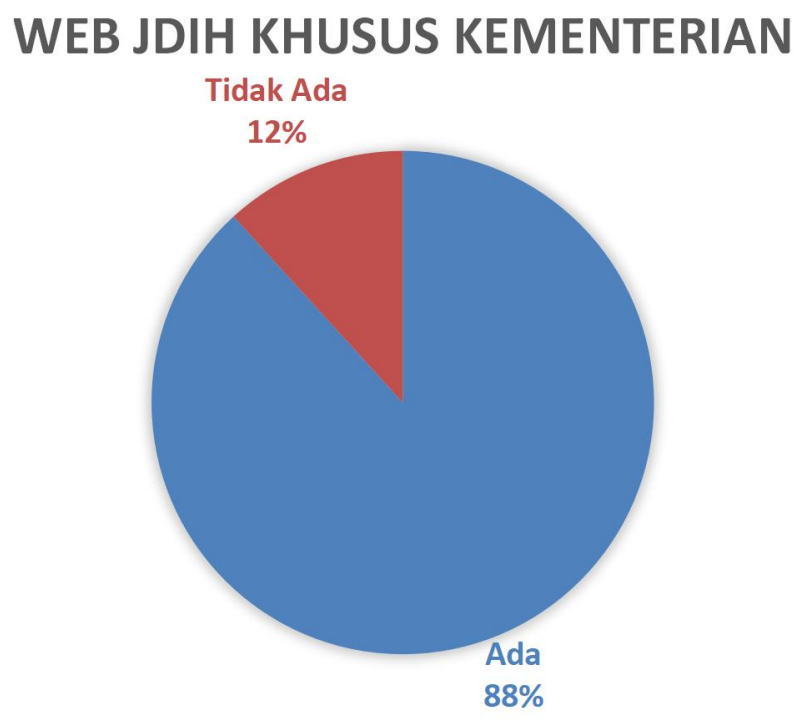

Gambar 2 Diagram ketersediaan website JDIH kementerian

Koordinator Bidang Perekonomian.

Dari hasil identifikasi, kementerian-kementerian yang belum memiliki Web JDIH tersebut, menggunakan $w e b$ resmi sebagai sarana untuk mendokumentasikan produk hukum mereka.

Tidakadanya web JDIH Kementerian sebenarnya tidak berpengaruh dalam penyampaian informasi, namun dengan adanya web tersebut informasi mengenai JDIH Kementerian dapat terintegrasi dengan JDIH Nasional yang dapat mempermudah pencarian produk hukum. Website JDIH Kementerian ini berbeda setiap kementeriannya, tidak ada standar khusus untuk bagaimana tampilan Web yang seharusnya dan bagaimana system web-nya bekerja. Dari hal tersebut, maka terkadang terlihat ketimpangan antara Website JDIH suatu kementerian dengan kementerian lain. Beberapa Website ada yang terlihat sangat sederhana dan terkesan kaku, sedangkan beberapa Website terlihat menarik dan modern. Dari perbandingan dengan dua contoh dibawah dapat dilihat adanya ketimpangan pada tampilan Website JDIH kementerian tersebut. 


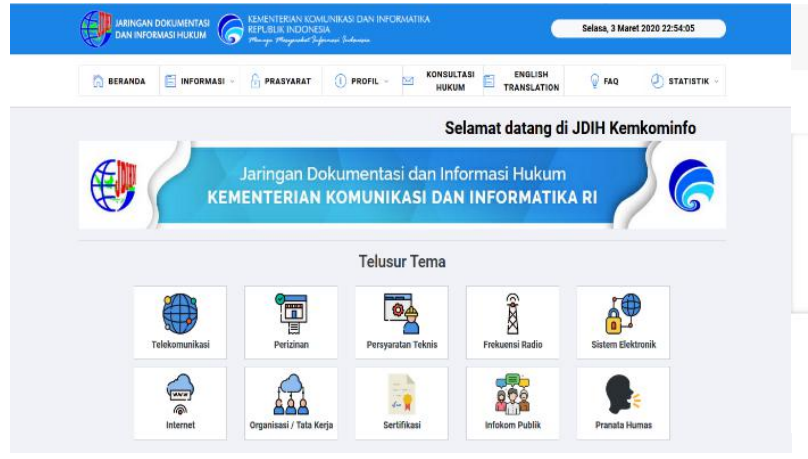

Gambar 3 Tampilan Website JDIH Kemkominfo

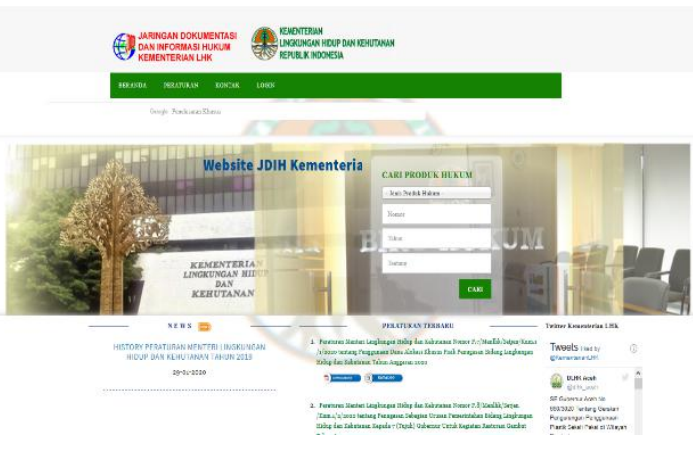

Gambar 4 Tampilan Website JDIH Kemenlhk

Perbedaan tersebut memang hanya sebatas pada tampilan saja, segala fungsionalitas website telah memenuhi tujuan diadakannya JDIH itu sendiri. Dari dasar tersebut ditemukan bahwa memang framework yang digunakan oleh pengembang Website JDIH Kementerian berbeda-beda. Sehingga hasil akhir dari bentuk dan tampilan website JDIH Kementerian di Indonesia sangatlah beragam. Perbedaan Framework ini terdapat di tiga kategori Framework yang dapat di deteksi oleh Wappalyzer yaitu JavaScript Framework, UI Framework, dan Web Framework. Untuk pembahasan selanjutnya, kami akan menganalisis 30 website Kementerian yang memiliki domain JDIH dan terintegrasi dengan JDIH Nasional.

\section{Javascript Framework}

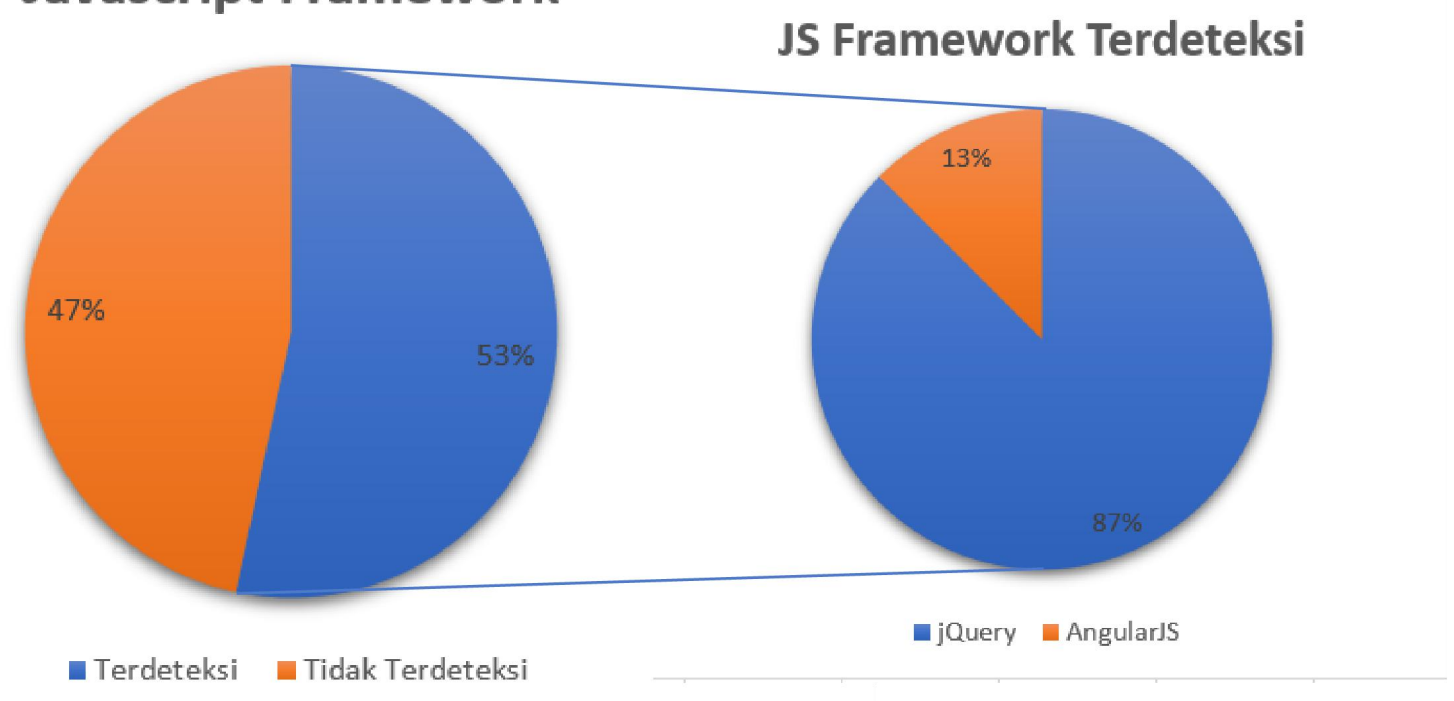

Gambar 5 Diagram JavaScript Framework

Berdasarkan hasil pada Gambar 5, terdapat 53\% website JDIH terdeteksi telah menggunakan JavaScript Framework. Diantara website tersebut terdapat 2 macam JavaScript Framework yang digunakan yaitu, AngularJS dan JQuery. JQuery menjadi framework yang sering digunakan karena JQuery merupakan framework javascript yang paling umum digunakan para pengembang web. Sebanyak lebih dari $90 \%$ website menggunakan JQuery dan hanya 0,5\% menggunakan Angular[13]. 
JQuery merupakan framework Javascript yang berisikan kumpulan kode dan fungsi Javascript yang siap dipakai dalam pembuatan aplikasi web. JQuery memiliki beberapa kelebihan diantaranya, kompatibel dengan kebanyakan web browser, memiliki dokumentasi dan tutorial yang lengkap, ukuran file yang kecil yaitu 20kb, dan gratis [14].

Sedangkan AngularJS sendiri digunakan oleh pengembang web karena kemampuannya dalam meng-ekstend HTML suatu web. Kedua framework ini dapat digunakan Bersama, namun tidak disarankan. Hal ini dikarenakan kedua framework ini mengelola DOM dalam suatu web[15], jadi perlu berhati-hati jika kedua framework ini akan digunakan bersamasama.

\section{UI Framework}

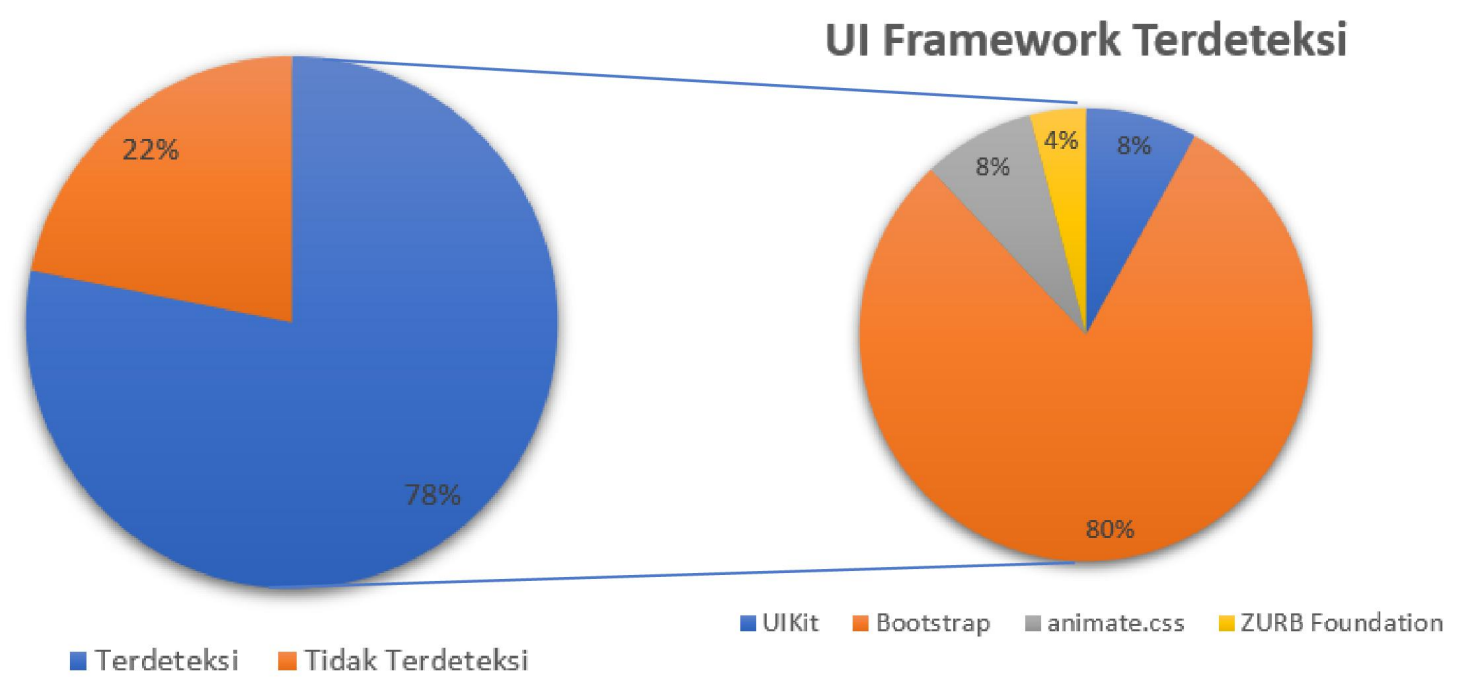

Gambar 6 Diagram UI Framework

Pada Gambar 6, berdasarkan UI Framework yang terdeteksi, Bootstrap menduduki urutan teratas sebagai framework yang paling banyak digunakan dalam website JDIH Kementerian dengan persentase sebanyak $80 \%$, diikuti animate.css, UIKit, dan terakhir ZURB Foundation. Selain itu, terdapat website JDIH Kementerian yang menggunakan UI Framework lebih dari satu. Sebagai contoh, website JDIH Kementerian Ketenagakerjaan (https://jdih.kemnaker.go.id/) dan JDIH Sekretariat Negara (https://jdih.setneg.go.id/) menggunakan framework animate.css dan Bootstrap sebagai penunjang UI di website-nya.

Bootstrap adalah framework yang dikembangkan pengembang Twitter pada pertengahan tahun 2010 dan terus berkembang sampai saat ini dan telah menjadi salah satu front-end framework yang paling populer dan merupakan proyek open-source di dunia. Bootstrap terdiri atas bahasa html dan css yang menyediakan efek javascript yang dibangun menggunakan jQuery[16]. 


\section{Web Framework}

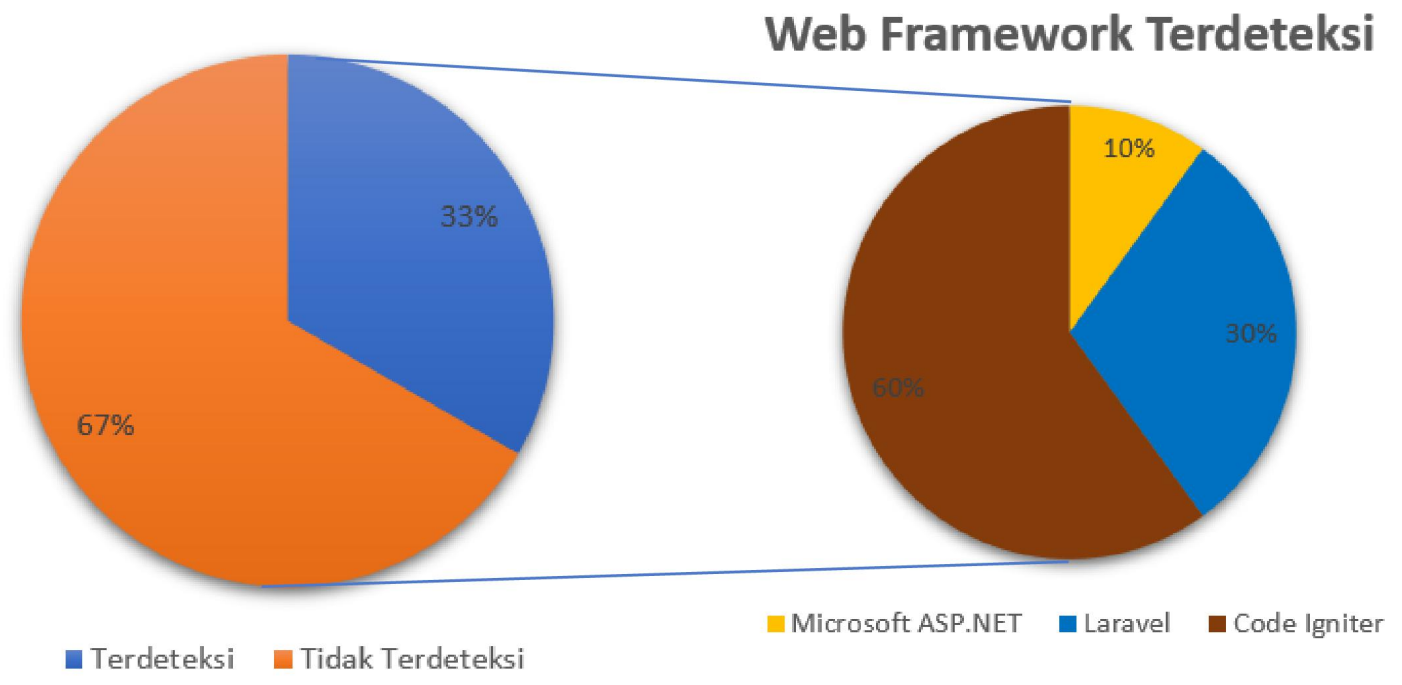

Gambar 7 Diagram Web Framework

Berdasarkan 30 website JDIH kementerian yang dianalisis terdeteksi 33\% menggunakan PHP framework untuk keperluan membentuk backend dari keperluan yang diperlukan website.

Tabel 2 Persentase Penggunaan Web Framework dari Terbesar hingga Terkecil

\begin{tabular}{|c|l|c|}
\hline No. & \multicolumn{1}{|c|}{ Web Framework } & Persentase \\
\hline 1. & Code Igniter & $60 \%$ \\
\hline 2. & Laravel & $30 \%$ \\
\hline 3. & Microsoft ASP.NET & $10 \%$ \\
\hline
\end{tabular}

Dalam menggunakan framework untuk membangun sebuah website menggunakan sebuah metode yang disebut MVC (Model-View-Controller). Dengan menggunakan metode MVC membagi logika pemrograman dengan presentasi [17] sehingga memudahkan developer dalam membuat website. Ketiga framework yang digunakan tersebut dapat menggunakan metode MVC dalam pengaplikasiannya. 


\section{KETERSEDIAAN SEARCHBOX}

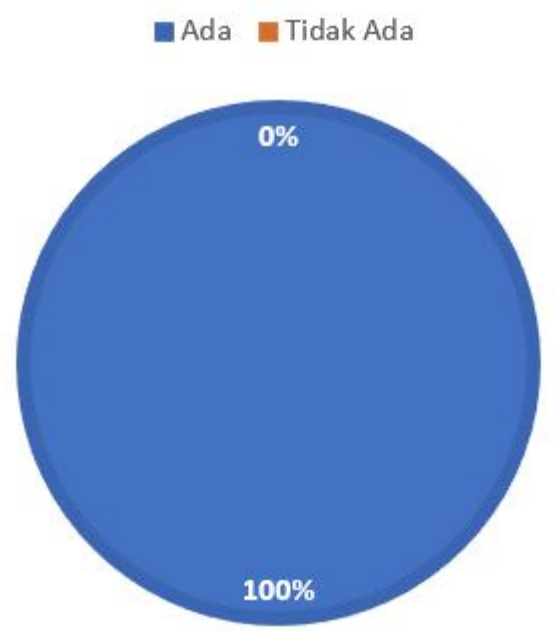

Gambar 8 Diagram Ketersediaan Searchbox

Untuk memperlancar tujuan dokumentasi dari undang-undang, seluruh website JDIH kementerian telah mengaplikasikan fitur searchbox untuk mencari undang-undang yang tersedia dalam Website tersebut, sehingga memudahkan pengguna website dalam menelusuri dan menemukan undang-undang dan segala bentuk peraturan yang berkaitan dengan kementerian secara efisien.

\section{BENTUK DOKUMEN PERATURAN}

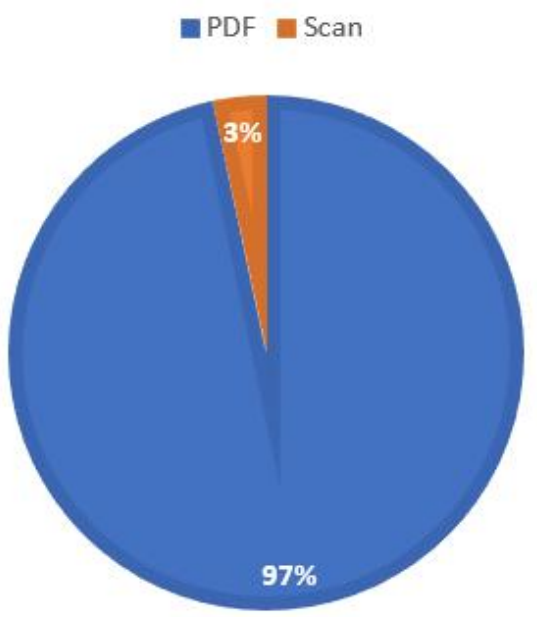

Gambar 9 Diagram Bentuk Dokumen Peraturan

Dalam menyajikan produk hukum, jenis dokumen yang digunakan pada website JDIH Kementerian ditampilkan dalam bentuk PDF sebanyak 97\% dan scan dokumen sebanyak 3\%, di mana dokumen berbentuk scan hanya digunakan pada website JDIH Kementerian Luar Negeri (https://jdih.kemlu.go.id). Dokumen berjenis PDF memudahkan pengguna untuk melakukan sitasi maupun pencarian undang-undang yang sekiranya relevan dengan kata kunci yang digunakan pengguna website. Sebaliknya, jika dokumen peraturan 
tersebut diberikan dalam bentuk scan, maka kemungkinan besar pengguna akan kesulitan mencari peraturan tersebut.

Berdasarkan hasil yang didapatkan dari analisis di atas, kami menemukan bahwa terdapat $12 \%$ Kementerian yang belum memiliki website khusus JDIH untuk dokumentasi hukum, meski begitu, Kementerian tersebut telah memiliki website dengan domain lain untuk menyebarkan produk hukumnya. Selain itu, kami menemukan bahwa masih terdapat implementasi yang kurang pada web framework di website JDIH Kementerian (sebanyak 67\% framework belum terdeteksi), untuk itu kami menyarankan kepada pengembang website untuk mengimplementasikan web framework karena hal tersebut dapat mengurangi bug dan mengehemat waktu pengembangan website, dan hal itu akan memberikan dampak yang baik dalam hal pemeliharaan dan perbaikan untuk selanjutnya.

\section{SIMPULAN}

Website JDIH Kementerian menggunakan framework yang beragam atau bahkan tidak menggunakan framework sama sekali, maka dari hasil analisis tersebut dapat disimpulkan bahwa belum terdapat standardisasi untuk membangun website JDIH khusus Kementerian. Penggunaan framework dalam pembangunan sebuah web terbukti mempermudah pengembang membangun web. Maka dari itu penggunaan framework benar - benar harus dipertimbangkan oleh pengembang web. Sudah banyak penelitian yang membandingkan kelebihan dan kekurangan setiap framework web yang ada, sehingga pengembang dapat memaksimalkan fungsionalitas web tanpa meniadakan sisi estetika dari web tersebut.

Untuk kemudahan mencari suatu produk hukum tertentu, Website JDIH Kementerian telah cukup memenuhi tujuan tersebut. Hal ini dikarenakan penggunaan framework dalam Website JDIH Kementerian telah sesuai tujuan. Serta hal ini ditunjang dengan adanya fitur searchbox untuk mencari produk hukum berdasarkan kriteria tertentu. Pencarian semacam ini akan lebih efektif dan efisien dengan penggunaan framework terutama untuk bagian javascript dari web.

Rekomendasi penulis adalah dibuatnya standardisasi dalam pembangunan Web JDIH Kementerian. Standardisasi tersebut terutama pada penggunaan framework tertentu pada bagian javascript dan User Interface. Hal tersebut dikarenakan javascript menangani pengelolaan web dengan database, dimana database tersebut berisi produk hukum kemeterian. Sedangkan penggunaan framework User Interface bertujuan agar pengguna/ pengunjung $\mathrm{Web}$ JDIH Kementerian dapat dengan mudah mencari produk hukum tertentu dan bernavigasi di web.

\section{UCAPAN TERIMAKASIH}

Puji syukur kami panjatkan kepada Allah SWT yang telah memberikan rahmat dan hidayatNya sehingga kami dapat menyelesaikan paper ini dengan baik. Tak lupa kami mengucapkan terima kasih kepada dosen pengampu mata kuliah Etika Profesi, Ibu Nur Aini Rakhmawati yang telah membimbing kami dalam menyusun topik ini. Semoga paper yang kami susun ini dapat bermanfaat bagi para pembaca. 


\section{DAFTAR PUSTAKA}

[1] Pemerintah Indonesia, Peraturan Presiden No 68 Tahun 2019 Tentang Organisasi Kementerian Negara. Indonesia, 2019.

[2] Pemerintah Indonesia, Undang-Undang No 14 Tahun 2008 Tentang Keterbukaan Informasi Publik. Indonesia, 2008.

[3] Pemerintah Indonesia, Peraturan Presiden No 33 Tahun 2012 Tentang Jaringan Dokumentasi Dan Informasi Hukum Nasional. Indonesia, 2012.

[4] N. A. Rakhmawati, S. Harits, D. Hermansyah, and M. A. Furqon, "A Survey of Web Technologies Used in Indonesia Local Governments," Sisfo, 2018, doi: 10.24089/j.sisfo.2018.05.003.

[5] Pemerintah Indonesia, Instruksi Presiden No 3 Tahun 2003 Tentang Kebijakan Dan Strategi Nasional Pengembangan E-Goverment. Indonesia, 2003.

[6] D. H. Curie, J. Jaison, J. Yadav, and J. R. Fiona, “Analysis on Web Frameworks,” in Journal of Physics: Conference Series, 2019, vol. 1362, no. 1, p. 12114.

[7] C. L. Mariano, "Benchmarking javascript frameworks," 2017.

[8] P. Japikse, K. Grossnicklaus, and B. Dewey, Building Web Applications with Visual Studio 2017: Using. NET Core and Modern JavaScript Frameworks. Apress, 2017.

[9] M. N. El Ghiffary, T. D. Susanto, and A. H. Prabowo, "Analisis Komponen Desain Layout, Warna, dan Kontrol pada Antarmuka Pengguna Aplikasi Mobile Berdasarkan Kemudahan Penggunaan (Studi Kasus: Aplikasi Olride)," J. Tek. ITS, vol. 7, no. 1, pp. A143--A148, 2018.

[10] B. Sidik, "Pemrograman Web dengan PHP, Informatika," Pemrograman Web, 2012.

[11] H. He, L. Chen, and W. Guo, "Research on Web Application Vulnerability Scanning System based on Fingerprint Feature," 2017, doi: 10.2991/mecae-17.2017.27.

[12] Y. N. Rahman, R. M. Hadi, M. Nabilah, M. H. Waskito, and N. A. Rakhmawati, "Data Penggunaan Framework Pada Website JDIH Kementerian Indonesia," Mar. 2020, doi: 10.5281/ZENODO.3700713.

[13] W3Techs, "Market share yearly trends for JavaScript libraries," w3techs.com. 2011, Accessed: Feb. 28, 2020. [Online]. Available: https://w3techs.com/technologies/history_overview/Javascript_library/ms/y.

[14] M. A. Ganiardi, I. Salamah, and R. D. Kusumanto, "JQUERY SEBAGAI KOMPONEN USABILITAS ANTARMUKA APLIKASI WEB," J. Poli-Teknologi, vol. 14, no. 2, 2015.

[15] J. Chaffer, Learning JQuery 1.3: Better Interaction and Web Development with Simple JavaScript Techniques. Packt Publishing Ltd, 2009.

[16] M. R. Adhiasta and S. T. Muhammad Kusban, "Perancangan Informasi Batik Solo Berbasis Bootstrap." Universitas Muhammadiyah Surakarta, 2016.

[17] R. Irawan, "Implementasi Framework Codeignter Untuk Pengembangan Website Pada Dinas Perkebunan Provinsi Kalimantan Tengah," J. Saintekom, vol. 7, no. 1, pp. 67-80, 2017 